\title{
Effects of arginine vasopressin on the urine proteome in rats
}

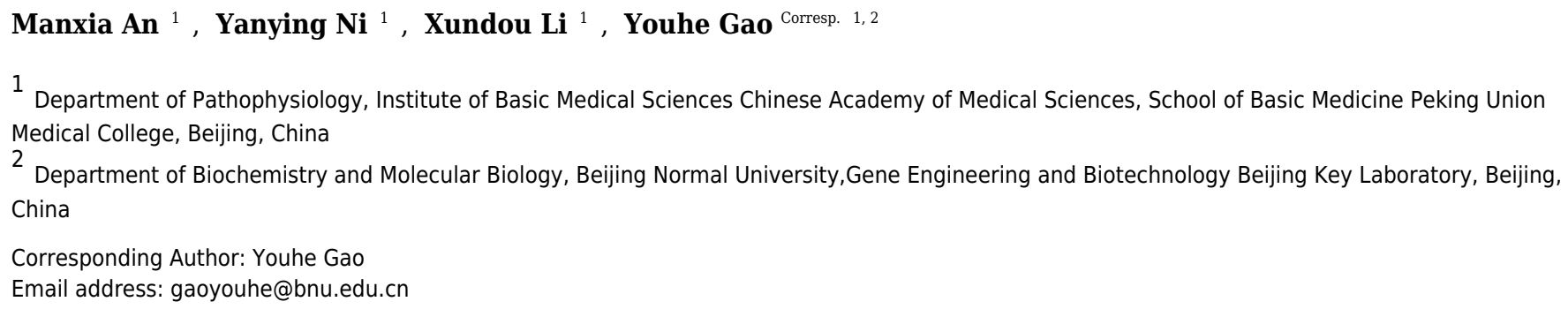

Biomarkers are the measurable changes associated with a physiological or pathophysiological process. The content of urine frequently changes because it is not controlled by homeostatic mechanisms, and these alterations can be a source of biomarkers. However, urine is affected by many factors. In this study, vasoconstrictor and antidiuretic arginine vasopressin (AVP) were infused into rats using an osmotic pump. The rats' urinary proteome after one week of infusion was analyzed by label-free LC-MS/MS. A total of 408 proteins were identified; among these proteins, 8 and 10 proteins had significantly altered expression in the low and high dose groups, respectively, compared with the control group using the one-way ANOVA analysis followed by post hoc analysis with the least significant difference (LSD) test or Dunnett's T3 test. Three differential proteins were described in prior studies as related to AVP physiological processes, and 9 differential proteins are known disease biomarkers. Sixteen of the 17 differential proteins have human orthologs. These results suggest that we should consider the effects of AVP on urinary proteins in future urinary disease biomarker researches. The study data provide clues regarding underlying mechanisms associated with AVP for future physiological researches on AVP. This study provide a sensitive changes associated with AVP. However, the limitation of this result is that the candidate biomarkers should be further verified and filtered. Large clinical samples must be examined to verify the differential proteins identified in this study before these proteins are used as biomarkers for pathological AVP increased diseases, such as syndrome of inappropriate antidiuretic hormone secretion (SIADH). 


\section{Effects of arginine vasopressin on the urine proteome in rats}

2

3 Manxia $\mathrm{An}^{1}$, Yanying $\mathrm{Ni}^{1}$, Xundou $\mathrm{Li}^{1}$, Youhe $\mathrm{Gao}^{1,2}$

$4{ }^{1}$ Department of Pathophysiology, Institute of Basic Medical Sciences Chinese Academy of Medical Sciences,

5 School of Basic Medicine Peking Union Medical College, Beijing, China

62 Department of Biochemistry and Molecular Biology, Beijing Normal University, Gene Engineering and

7 Biotechnology Beijing Key Laboratory, Beijing, China

8

9

10

11

12

13

14

Corresponding Author:

Youhe Gao

Email address: gaoyouhe@pumc.edu.cn; gaoyouhe@bnu.edu.cn 
34

Abstract: Biomarkers are the measurable changes associated with a physiological or pathophysiological process. The content of urine frequently changes because it is not controlled by homeostatic mechanisms, and these alterations can be a source of biomarkers. However, urine is affected by many factors. In this study, vasoconstrictor and antidiuretic arginine vasopressin (AVP) were infused into rats using an osmotic pump. The rats' urinary proteome after one week of infusion was analyzed by label-free LC-MS/MS. A total of 408 proteins were identified; among these proteins, 8 and 10 proteins had significantly altered expression in the low and high dose groups, respectively, compared with the control group using the one-way ANOVA analysis followed by post hoc analysis with the least significant difference (LSD) test or Dunnett's T3 test. Three differential proteins were described in prior studies as related to AVP physiological processes, and 9 differential proteins are known disease biomarkers. Sixteen of the 17 differential proteins have human orthologs. These results suggest that we should consider the effects of AVP on urinary proteins in future urinary disease biomarker researches. The study data provide clues regarding underlying mechanisms associated with AVP for future physiological researches on AVP. This study provide a sensitive changes associated with AVP. However, the limitation of this result is that the candidate biomarkers should be further verified and filtered. Large clinical samples must be examined to verify the differential proteins identified in this study before these proteins are used as biomarkers for pathological AVP increased diseases, such as syndrome of inappropriate antidiuretic hormone secretion (SIADH).

\section{Introduction}

Biomarkers are the measurable changes associated with a physiological or pathophysiological process (Gao 2013). Blood is under the homeostatic control of the body. Renal filtration, reabsorption of solutes, and excretion of water are examples of homoeostatic control of blood which in turn affect the composition of urine. Without homeostasis, urine contains many changes. Therefore urine should be a better source of biomarkers. Additionally, urine can be obtained easily and noninvasively. It has been used in studies to detect disease biomarkers, such as kidney disease (Pejcic et al. 2010), cardiovascular disease (Delles et al. 2011) and liver disease (Trovato et al. 2015). However, many non-disease factors, including age, gender, lifestyle and medications, can affect changes in urine (Wu \& Gao 2015). These factors can interfere or mask changes caused by the disease itself, increasing the difficulty of identifying reliable and disease-specific biomarkers. In clinical studies, age, gender and other factors can be 
66

67

balanced to a certain degree by the experimental design. The influence of medications is difficult to assess and balance between the experimental and control groups because only patients in the disease group usually receive medication treatment. It is possible that changes caused by medication are incorrectly considered to be disease biomarkers. Therefore, the effect of medications should be separately studied to facilitate identifying disease-specific biomarkers.

AVP, which is also called antidiuretic hormone, is a polypeptide hormone consisting of 9 amino acids (Kounin \& Bashir 2000). It is synthesized and secreted in the supraoptic and paraventricular nuclei of the hypothalamus and is released into the blood to participate in physical activities because of certain physiological stimuli. Its two most important physiological functions are as a vasoconstrictor and an antidiuretic (Kounin \& Bashir 2000). AVP is also involved in a variety of physiological processes, including physiological stress (Coverdill et al. 2012; Zelena et al. 2009), memory (Nabe et al. 2007), thermoregulation (Bicego-Nahas et al. 2000) and pain regulation (Madrazo et al. 1987). In clinical applications, AVP is used for the treatment of many diseases, such as diabetes insipidus, hepatorenal syndrome, portal venous hypertension, bleeding disorders, septic shock and cardiopulmonary resuscitation (Treschan \& Peters 2006).

SIADH has common clinical symptoms and can be complicated by diseases characterized by abnormal increases in AVP secretion (Frouget 2012). Excessive AVP secretion can promote the opening of water channels in the renal collecting duct and distal convoluted tubule (DCT), thereby increasing water reabsorption, reducing urine volume, increasing urine osmolality and decreasing serum sodium levels. Continuous AVP infusion can be used to establish a rat SIADH model for identification of SIADH urinary markers(Verbalis 1984).

Studying the effects of AVP on urine can achieve the following goals: (1) providing some clues for understanding its physiological functions; (2) establishing a reference for urinary biomarker research when AVP is used as a medication in studies; and (3) identifying potential biomarkers for pathological increases in AVP in diseases such as SIADH.

In this study, AVP (10 $\mathrm{ng} / \mathrm{h}$ and $50 \mathrm{ng} / \mathrm{h})$ was infused into rats with an osmotic pump. The urine from the model rats and the controls was analyzed by label-free LC-MS/MS one week after AVP infusion. Using rat models can minimize the influence of other factors by strictly controlling the experimental conditions so that the AVP is the single influential factor. Another advantage of using rat models is that more reliable candidate biomarkers can be obtained from a small number of samples (Gao 2014). 
Materials and methods

Animal experiments

Male Sprague-Dawley rats (160-180 g) were purchased from the Institute of Laboratory Animal

Science, Chinese Academy of Medical Science (Beijing, China). The rats were fed a standard

laboratory diet and had free access to water. They were housed in standard temperature $\left(22 \pm 1^{\circ} \mathrm{C}\right)$ and humidity (65\%-70\%) conditions. The animal experiments were approved by the Institute of Basic Medical Sciences Animal Ethics Committee, Peking Union Medical College (Animal Welfare Assurance Number: ACUC-A02-2013-015). 
130

131

132

133

134

135

136

137

138

139

140

141

142

143

144

145

146

147

148

149

150

151

152

153

154

155

156

157

158

159

160

161

randomly from each group for urinary proteome profiling by LC-MS/MS.

\section{Extraction of urinary protein}

Urine was centrifuged at $2000 \mathrm{~g}$ for $30 \mathrm{~min}$ immediately after collection to remove the cell debris. The supernatant was centrifuged at $12,000 \mathrm{~g}$ for $30 \mathrm{~min}$. Three volumes of acetone were added to the supernatant after removing the pellets, and precipitation was allowed to occur overnight at $-20^{\circ} \mathrm{C}$ followed by centrifugation at $12000 \mathrm{~g}$ for $30 \mathrm{~min}$. The pellets were resuspended in lysis buffer ( $8 \mathrm{M}$ urea, $2 \mathrm{M}$ thiourea, $50 \mathrm{mM}$ Tris, and $25 \mathrm{mM}$ dithiothreitol (DTT)) for $2 \mathrm{~h}$ at $4{ }^{\circ} \mathrm{C}$. The solution was centrifuged at $12000 \mathrm{~g}$ for $30 \mathrm{~min}$ and the supernatant was collected. The protein concentrations were determined using the Bradford method.

\section{SDS-PAGE analysis}

Thirty micrograms of protein from each sample were mixed with sample buffer and incubated at $96^{\circ} \mathrm{C}$ for $10 \mathrm{~min}$. The protein samples were then loaded onto $12 \%$ SDS-PAGE. The gel was stained using Coomassie Brilliant Blue.

\section{Urine sample preparation and LC-MS/MS}

Urinary proteins were digested with trypsin using the filter-aided sample preparation method (Wisniewski et al. 2009). One hundred micrograms of protein were deposited onto a $10 \mathrm{kD}$ filter membrane (Pall, Port Washington, NY, USA). Then, urea buffer (UA; $8 \mathrm{M}$ urea and $0.1 \mathrm{M}$ Tris$\mathrm{HCl}, \mathrm{pH}$ 8.6) and ammonium bicarbonate $(25 \mathrm{mM})$ were added to the membrane and centrifuged at $14000 \mathrm{~g}$ for $40 \mathrm{~min}$ at $18^{\circ} \mathrm{C}$ to wash the samples. The samples were reduced by incubation with $20 \mathrm{mM}$ dithiothreitol at $37^{\circ} \mathrm{C}$ for $1 \mathrm{~h}$ and alkylated by $50 \mathrm{mM}$ in iodoacetamide (IAA) in the dark for 40 minutes. UA and ammonium bicarbonate were added and centrifuged to remove the remaining DTT and IAA. Mass spec grade trypsin (Trypsin Gold, Mass Spec Grade, Promega, Fitchburg, WI, USA) was added to the filter membrane at an enzyme-to-protein ratio of 1:50 and incubated at $37^{\circ} \mathrm{C}$ for $13 \mathrm{~h}$. The digested peptides were obtained by centrifugation, desalted with Oasis HLB cartridges (Waters, Milford, MA, USA) and dried by vacuum evaporation.

One microgram of peptides was loaded onto a reversed-phase microcapillary column by EASY-nLC 1200 UHPLC system and eluted with a gradient of 5-28\% mobile phase B $(0.1 \%$ formic acid and $99.9 \%$ acetonitrile; flow rate of $0.3 \mathrm{~mL} / \mathrm{min}$ ) for $60 \mathrm{~min}$. The eluted peptides were analyzed by Thermo Orbitrap Fusion Lumos MS (Thermo Fisher Scientific, Bremen, 
162 Germany). Each peptide sample was analyzed three times as technical replicates.

163

164

165

166

167

168

169

170

171

172

\section{MS data analysis}

MS data were retrieved using the mascot software (version 2.5.1, Matrix Science, London, UK) and searched against the Swissprot_2014_07 database (taxonomy: Rattus, containing 7787 sequences). Trypsin was selected as the digestion enzyme, and two missed trypsin cleavage sites were allowed. Carbamidomethylation of cysteines was selected as a fixed modification. The fragment mass tolerance was set to $0.6 \mathrm{Da}$, and the parent mass tolerance was set to $10 \mathrm{ppm}$. Mascot search results were screened and integrated using scaffold software (version 4.4.8, Proteome Software Inc., Portland, Oregon, USA). The peptide identification and protein identification false discovery rates were set to less than $1 \%$, with each protein containing at least 2 identified peptides. Differential proteins between the control and AVP infusion groups were identified by quantitatively analyzing spectral counts. The Ensembl Compare database was searched to identify orthologous human proteins for these differential urinary proteins as reported (Vilella et al. 2009), and the human orthologs were then compared with the human core urinary proteome (Nagaraj \& Mann 2011).

\section{Hierarchical clustering of quantitative data}

Hierarchical cluster analysis was used to understand the overall changes in proteins between groups and assess the parallelism and variations among technical replicates. An average-linkage hierarchical clustering of the top 280 proteins (after excluding proteins with low spectral count) was performed and visualized by R's gplot v3.01 package to create heat maps via the heatmap.2, the default hierarchical clustering method in hclust is "complete method".

\section{Biological function analysis of differential proteins}

Biological functions of differential proteins, including molecular functions, biological processes and cellular components, were analyzed using the PANTHER classification system (http://www.pantherdb.org/).

\section{Statistical analysis}

The P value was analyzed by the Statistical Package for Social Studies (SPSS) 22.0. The differences in physiological indicators and urinary proteins were assessed using the SPSS 
194

195

196

197

198

199

200

201

202

203

204

205

206

207

208

209

210

211

212

213

214

215

216

217

218

219

220

221

222

223

224

225

software by one-way ANOVA followed by post hoc analysis with the least significant difference (LSD) test or Dunnett's T3 test. The difference between groups was considered significant when the $\mathrm{P}$ value was equal to or less than 0.05 .

\section{Results}

\section{Weight gain and urine protein-to-creatinine ratio}

There were no significant difference of weight gains in the normal, low-dose, and high-dose groups by one week after AVP infusion (Fig. 1 A). The urine protein-to-creatinine ratio was slightly higher in the low-dose group and the high-dose group than in the control group, although these differences were not statistically significant (Fig. 1 B).

\section{Urine volume and urinary osmolality}

The $24 \mathrm{~h}$ urine volume of rats in the AVP infusion group was significantly less than that of those in the control group, and the urine volume of the rats in the high-dose group was significantly less than that of those in the low-dose group (Fig. $1 \mathrm{C}$ ). The urinary osmolality of rats in the AVP infusion group was significantly higher than that of those in the control group.

Additionally, urinary osmolality of rats was higher in the high-dose group than in the low-dose group, although this difference was not statistically significant (Fig. 1 D).

\section{SDS-PAGE analysis}

Thirty microgram of urinary proteins were analyzed in SDS-PAGE to observe the protein distribution. The SDS-PAGE gel showed that there was no significant degradation of these samples (Figure 2). The gel bands were not excised for mass spectrometric analysis. A different aliquot (100 micrograms) of urinary proteins were analyzed by mass spectrometry. No bands with consistent differences between the control and AVP infusion groups were observed in the SDS-PAGE analysis (Fig. 2).

\section{Proteomics analysis}

Urine specimens of three rats from the control, low-dose and high-dose groups were analyzed by LC-MS/MS. Each sample was analyzed three times as technical replicates. Differential proteins were identified by semi-quantitative analyses of spectral counts (Liu et al. 2004; Old et al. 2005; Schmidt et al. 2014). The spectral count for each protein was calculated based on the mean 
226

227

228

229

230

231

232

233

234

235

236

237

238

239

240

241

242

243

244

245

246

247

248

249

250

251

252

253

254

255

256

257

spectral count of the proteins from 3 replicates.

A total of 408 proteins were identified in the three groups. The identified proteins are shown in Supplemental table 1. Forty-nine proteins significantly changed between control group and AVP infusion groups ( $\mathrm{P}$ by ANOVA $\leqslant 0.05)$. Compared to the control group, 21 differential proteins in the low-dose group and 37 in high-dose group were significantly different. Nine proteins were significantly changed in both groups.

To identify the most significantly differential protein, the following more stringent criteria were chosen: (1) P by ANOVA $\leqslant 0.05$, (2) fold change $\geqslant 1.5$, and (3) spectral count for each sample $\geqslant 4$ in at least one group. Seventeen differential proteins were identified between control group and AVP infusion groups by these criteria. Eight differential proteins in the low-dose group and 10 in the high-dose group were identified relative to the control group (Table 1 and 2). One protein was significantly changed in both groups.

\section{Hierarchical clustering of quantitative data}

As indicated in Fig. 3, the high-dose group was easily distinguishable from the low-dose group and the control group. The three technical replicates for each sample can also be readily identified on the heatmap.

\section{Biological function analysis of differential proteins}

Biological functions of 49 differential proteins that significantly changed between control group and AVP infusion groups were analyzed. The major molecular functions of the differential proteins include catalytic activity, binding and receptor activity. The differential proteins' main biological processes include cellular processes, biological regulation and developmental processes. The differential proteins' main cellular components include cell parts, organelles and extracellular regions (Fig. 4).

\section{Differential proteins reported to be associated with AVP}

Three differential proteins have been reported to be related to the functions of AVP. Increased expression of osteopontin in rat aortic adventitial fibroblasts can be induced by urotensin II (Zhang et al. 2011), which has vasoconstrictive functions similar to those of vasopressin. In this study, osteopontin in urine was 6-fold higher in the high-dose group than in the control group. Calbindin, as $\mathrm{Ca} 2+-$ buffer protein, can buffer $\mathrm{Ca}^{2+}$ concentrations within cells and thereby 
258 prevent cell injuries caused by high intracellular $\mathrm{Ca}^{2+}$ (Schwaller 2009). Calbindin localized to

259

260

261

262

263

264

265

266

267

268

269

270

271

272

273

274

275

276

277

278

279

280

281

282

283

284

285

286

287

288

289 the DCT and the connecting tubule can regulate calcium transport and reabsorption (Hsin et al. 2006; Lambers et al. 2006).

It is well known that AVP can improve the permeability to water of the DCT and the connecting tubule and increase $\mathrm{NaCl}$ reabsorption. The $\left.\mathrm{Na}\left({ }^{+}\right) / \mathrm{H}^{+}\right)$exchange regulatory cofactor NHE-RF3 plays an important role in regulating cell ion transport and membrane fluidity (Kato et al. 2005). NHE-RF3 also can mediate the formation of NHE3 (Yang et al. 2014), which is the major transporter in the proximal tubule that is involved in $\mathrm{Na}^{+}$reabsorption (Schultheis et al. 1998).

Calbindin in urine was 5.17-fold higher in the high-dose group than in the control group. NHE-RF3 in urine was 1.58 -fold higher in the high-dose group than in the control group.

The changes of these three differential proteins, same as other differential proteins, were not significant after the P values were adjusted by the Benjamini and Hochberger's method(Benjamini \& Hochberg 1995). The limitation of this result is that the candidate biomarkers should be further verified and filtered.

\section{Differential proteins as candidate biomarkers and their human orthologs}

Nine of the 17 differential proteins have been identified as disease biomarkers in urine.

Haptoglobin was identified as a biomarker for uranium nephrotoxicity (Malard et al. 2009), membranous nephropathy (Ngai et al. 2007), acute kidney injury (Zager et al. 2012), diabetic nephropathy (Rao et al. 2007), bladder carcinoma (Li et al. 2011), hepatic fibrosis (van Swelm et al. 2013) and acute phase response (Piras et al. 2014). Osteopontin can be used as a biomarker for ovarian cancer (Rainczuk et al. 2013), kidney stones (Bautista et al. 1996), bladder cancer (Yang et al. 2011) and drug-induced kidney injury (Phillips et al. 2016). Calbindin can serve as a biomarker for distal nephron segment injuries (Iida et al. 2014), nephrotoxicity (Hoffmann et al. 2010), acute kidney injury (Togashi et al. 2012)and drug-induced renal injury(Fuchs et al. 2014). Complement $\mathrm{C} 3$ can act as a biomarker of IgA nephropathy (Liu et al. 2014)and glomerulonephritis (Cumming et al. 1976). Pro-cathepsin H, regenerating islet-derived protein 3gamma, glyceraldehyde-3-phosphate dehydrogenase, CD166 antigen and beta-2-glycoprotein 1 can be biomarkers of polycystic kidney disease (Schaefer et al. 1996), urinary tract infection (Spencer et al. 2015), ureteropelvic junction obstruction (Mesrobian et al. 2010), type 1 diabetes (Suh et al. 2015) and Dent's disease (Cutillas et al. 2004), respectively. 
290

291

292

293

294

295

296

297

298

299

300

301

302

303

304

305

306

307

308

309

310

311

312

313

314

315

316

317

318

319

320

321

Sixteen of the 17 differential proteins have human orthologs. Twelve orthologs of these 16 proteins are part of the human core urinary proteome (Table 3). These results suggest that the effects of AVP on urinary proteins should be considered in future urinary disease biomarker researches.

\section{Candidate biomarkers for SIADH}

SIADH is often confused with cerebral salt wasting syndrome (CSWS) in the clinical setting, leading to difficulty in confirming its diagnosis. Therefore, identifying effective biomarkers can facilitate the differential diagnosis of SIADH and then contribute to the effective treatment of hyponatremia that connected with increased mortality (Corona et al. 2015). The differential proteins between the control and AVP infusion groups of this study may be used as candidate biomarkers to aid in diagnosing SIADH. Large clinical samples are needed to determine whether these proteins can actually be utilized in clinical testing.

\section{Discussion}

Urine is a good source of biomarkers since it contains many changes excluded from the body. Urinary proteins are important bearer of information in urine. Many urinary protein biomarkers have been identified in various disease, such as renal disease (Schanstra \& Mischak 2015), bladder cancer (Grossman et al. 2005), preeclampsia (Carty et al. 2011) and cardiovascular diseases (Delles et al. 2011). However some challenge exist in the urinary proteins biomarker studies such as standardization and normalization. The composition of the urinary proteins can be influenced by variation in sample handling process, including sample collection, protein extraction and protein digestion (Thongboonkerd et al. 2006). Standardized processes are considered to be beneficial for the integration analysis of the data from different sources. As for normalization, commercial software Scaffold (version 4.4.8, Proteome Software Inc., Portland, Oregon, USA) was used. The normalization method that Scaffold uses is to sum the "Unweighted Spectrum Counts" for each MS sample. These sums are then scaled so that they are all the same. The scaling factor for each sample is then applied to each protein group and adjusts its "Unweighted Spectrum Count" to a normalized "Quantitative Value".

Among the most significant differential proteins, only one protein was identified in both the low and high dose AVP groups, indicating that different mechanisms may be involved in responses to low and high doses of AVP, although both types of doses decrease urine volume 
322

323

324

325

326

327

328

329

330

331

332

333

334

335

336

337

338

339

340

341

342

343

344

345

346

347

348

349

350

351

352

353

and increase urine osmolality. In addition, we compared the results from this study with those of previous studies that investigated the effects of diuretics on urine (Li et al. 2014). Osteopontin excretion in urine significantly decreased after the rats were given the oral diuretic furosemide. In this study, osteopontin concentration was significantly elevated in urine from the high-dose AVP group, a result consistent with the finding that diuretics influence urine. Interestingly, haptoglobin concentrations in urine were significantly increased in both the high-dose AVP group in our study and in rats that were given the oral diuretic furosemide. Thus, the anti-diuretic and diuretic share some of the same physiological processes and do not always exhibit opposing effects.

One challenge related to diagnosing SIADH is differentiating SIADH from CSWS because these two syndromes have similar clinical manifestations (hyponatraemia, high urine osmolality, and high natriuresis). It is important to distinguish SIADH from CSWS because these two syndromes differ with respect to pathogenesis and treatment (Adrogue \& Madias 2012). Measuring effective arterial blood volume is the main approach used to differentiate between these two diseases (Palmer 2000). However, in clinical settings, it is difficult and expensive to determine effective arterial blood volume. Therefore, the efficiency of diagnosis and treatment would be improved by the identification of specific SIADH biomarkers. Differential proteins identified in this study can provide some clues for diagnose SIADH and future studies also be require to investigate biomarkers of CSWS and then aid the differential diagnosis.

The changes of the differential proteins (17 differential proteins) were not significant after the $\mathrm{P}$ values were adjusted and the more stringent criteria ( $\mathrm{P}$ by ANOVA $\leqslant 0.05,(2)$ fold change $\geqslant 1.5$, and $(3)$ spectral count for each sample $\geqslant 4$ )were used. However, the results before the $\mathrm{P}$ correction can provide some meaningful clues for future researches that study the physiological mechanism of AVP and SIADH biomarkers.

Cancer is a common cause of SIADH. Various tumors, including lung cancer, pancreatic cancer, duodenal cancer, brain tumors and hematological malignancies, can cause SIADH(Keenan 1999). Additionally, 7\%-12\% of small cell lung cancers are complicated by SIADH (Berghmans et al. 2000). SIADH symptoms may occur before imaging existing tumors. Thus, SIADH may be used as an indicator for the early diagnosis of tumors, especially non-small cell lung cancer. Thus, the differential proteins identified in this study are helpful for the early detection of tumors and the diagnosis of SIADH after be validated in a larger blinded study with test specimens and validation specimens. 
354

355

356

357

358

359

360

361

362

363

364

365

366

367

368

369

370

371

372

373

374

375

376

377

378

379

380

381

382

383

384

385

386

387

388

389

In this study, only the effect of AVP on male rats were analyzed. The previous study has demonstrated that vasopressin receptors gene AVPR2 is located on the X chromosome (Juul et al. 2014), suggesting that females may express more transcripts and receptors compared to males. Female rats should be included for future studies.

In conclusion, urinary proteins can be affected by AVP in vivo. Reports have indicated that several of the differential proteins identified in this study are associated with AVP; in addition, a number of the identified differential proteins have been recognized as disease biomarkers. These results suggest that several urinary biomarkers can be effected by AVP and thus we should consider the effects of AVP on urinary proteins in future urinary biomarker researches. The study data also provide clues regarding underlying mechanisms associated with AVP, and the identified differential proteins can be further studied to investigate their connections with AVP. Additionally, large clinical samples must be examined to verify that these differential proteins can actually be used as biomarkers of increases in pathological AVP in diseases such as SIADH.

(1)

(1)

3

74

375

7

\section{References:}

Adrogue HJ, and Madias NE. 2012. The challenge of hyponatremia. J Am Soc Nephrol 23:1140-1148. 10.1681/asn.2012020128

Bautista DS, Denstedt J, Chambers AF, and Harris JF. 1996. Low-molecular-weight variants of osteopontin generated by serine proteinases in urine of patients with kidney stones. J Cell Biochem 61:402-409. 10.1002/(SICI)1097-4644(19960601)61:3\&lt;402::AID-JCB7\&gt;3.0.CO;2-X

Benjamini Y, and Hochberg Y. 1995. Controlling the False Discovery Rate: A Practical and Powerful Approach to Multiple Testing. Journal of the Royal Statistical Society Series B (Methodological) 57:289-300.

Berghmans T, Paesmans M, and Body JJ. 2000. A prospective study on hyponatraemia in medical cancer patients: epidemiology, aetiology and differential diagnosis. Support Care Cancer 8:192-197.

Bicego-Nahas KC, Steiner AA, Carnio EC, Antunes-Rodrigues J, and Branco LG. 2000. Antipyretic effect of arginine 
390

391

392

393

394

395

396

397

398

399

400

401

402

403

404

405

406

407

408

409

410

411

412

413

414

415

416

417

418

419

420

421

422

423

424

425

426

427

428

429

430

431

432

433

434

435

436

437

438

439

440

441

442

vasotocin in toads. Am J Physiol Regul Integr Comp Physiol 278:R1408-1414.

Carty DM, Siwy J, Brennand JE, Zurbig P, Mullen W, Franke J, McCulloch JW, Roberts CT, North RA, Chappell LC, Mischak H, Poston L, Dominiczak AF, and Delles C. 2011. Urinary proteomics for prediction of preeclampsia. Hypertension 57:561-569. 10.1161/hypertensionaha.110.164285

Corona G, Giuliani C, Verbalis JG, Forti G, Maggi M, and Peri A. 2015. Hyponatremia improvement is associated with a reduced risk of mortality: evidence from a meta-analysis. PLoS One 10:e0124105. 10.1371/journal.pone.0124105

Coverdill AJ, McCarthy M, Bridges RS, and Nephew BC. 2012. Effects of Chronic Central Arginine Vasopressin (AVP) on Maternal Behavior in Chronically Stressed Rat Dams. Brain Sci 2. 10.3390/brainsci2040589

Cumming AD, Thomson D, Davidson AM, and Robson JS. 1976. Significance of urinary C3 excretion in glomerulonephritis. J Clin Pathol 29:601-607.

Cutillas PR, Chalkley RJ, Hansen KC, Cramer R, Norden AG, Waterfield MD, Burlingame AL, and Unwin RJ. 2004. The urinary proteome in Fanconi syndrome implies specificity in the reabsorption of proteins by renal proximal tubule cells. Am J Physiol Renal Physiol 287:F353-364. 10.1152/ajprenal.00018.2004

Delles C, Diez J, and Dominiczak AF. 2011. Urinary proteomics in cardiovascular disease: Achievements, limits and hopes. Proteomics Clin Appl 5:222-232. 10.1002/prca.201000125

Frouget T. 2012. [The syndrome of inappropriate antidiuresis]. Rev Med Interne 33:556-566. 10.1016/j.revmed.2012.07.005

Fuchs TC, Mally A, Wool A, Beiman M, and Hewitt P. 2014. An exploratory evaluation of the utility of transcriptional and urinary kidney injury biomarkers for the prediction of aristolochic acid-induced renal injury in male rats. Vet Pathol 51:680-694. 10.1177/0300985813498779

Gao Y. 2013. Urine-an untapped goldmine for biomarker discovery? Sci China Life Sci 56:1145-1146. 10.1007/s11427013-4574-1

Gao Y. 2014. Roadmap to the urine biomarker era. MOJ Proteomics Bioinform 1.

Grossman HB, Messing E, Soloway M, Tomera K, Katz G, Berger Y, and Shen Y. 2005. Detection of bladder cancer using a point-of-care proteomic assay. Jama 293:810-816. 10.1001/jama.293.7.810

Hoffmann D, Fuchs TC, Henzler T, Matheis KA, Herget T, Dekant W, Hewitt P, and Mally A. 2010. Evaluation of a urinary kidney biomarker panel in rat models of acute and subchronic nephrotoxicity. Toxicology 277:4958. 10.1016/j.tox.2010.08.013

Hsin YH, Cheng CH, Tzen JT, Wu MJ, Shu KH, and Chen HC. 2006. Effect of aristolochic acid on intracellular calcium concentration and its links with apoptosis in renal tubular cells. Apoptosis 11:2167-2177. 10.1007/s10495006-0289-0

lida T, Fujinaka H, Xu B, Zhang Y, Magdeldin S, Nameta M, Liu Z, Yoshida Y, Yaoita E, Tomizawa S, Saito A, and Yamamoto T. 2014. Decreased urinary calbindin 1 levels in proteinuric rats and humans with distal nephron segment injuries. Clin Exp Nephrol 18:432-443. 10.1007/s10157-013-0835-3

Juul KV, Bichet DG, Nielsen S, and Norgaard JP. 2014. The physiological and pathophysiological functions of renal and extrarenal vasopressin V2 receptors. Am J Physiol Renal Physiol 306:F931-940. 10.1152/ajprenal.00604.2013

Kato Y, Sai Y, Yoshida K, Watanabe C, Hirata T, and Tsuji A. 2005. PDZK1 directly regulates the function of organic cation/carnitine transporter OCTN2. Mol Pharmacol 67:734-743. 10.1124/mol.104.002212

Keenan AM. 1999. Syndrome of inappropriate secretion of antidiuretic hormone in malignancy. Semin Oncol Nurs 15:160-167.

Kounin G, and Bashir Q. 2000. Mechanism and role of antidiuretic hormone. Surg Neurol 53:508-510.

Lambers TT, Mahieu F, Oancea E, Hoofd L, de Lange F, Mensenkamp AR, Voets T, Nilius B, Clapham DE, Hoenderop JG, and Bindels RJ. 2006. Calbindin-D28K dynamically controls TRPV5-mediated Ca2+ transport. Embo $j$ 25:2978-2988. 10.1038/sj.emboj.7601186

Li H, Li C, Wu H, Zhang T, Wang J, Wang S, and Chang J. 2011. Identification of Apo-A1 as a biomarker for early diagnosis of bladder transitional cell carcinoma. Proteome Sci 9:21. 10.1186/1477-5956-9-21

Li X, Zhao M, Li M, Jia L, and Gao Y. 2014. Effects of three commonly-used diuretics on the urinary proteome. Genomics Proteomics Bioinformatics 12:120-126. 10.1016/j.gpb.2013.12.002

Liu H, Sadygov RG, and Yates JR, 3rd. 2004. A model for random sampling and estimation of relative protein abundance in shotgun proteomics. Anal Chem 76:4193-4201. 10.1021/ac0498563

Liu L, Zhang Y, Duan X, Peng Q, Liu Q, Zhou Y, Quan S, and Xing G. 2014. C3a, C5a renal expression and their receptors 
are correlated to severity of IgA nephropathy. J Clin Immunol 34:224-232. 10.1007/s10875-013-9970-6

Madrazo I, Franco-Bourland RE, Leon-Meza VM, and Mena I. 1987. Intraventricular somatostatin-14, arginine vasopressin, and oxytocin: analgesic effect in a patient with intractable cancer pain. Appl Neurophysiol 50:427-431.

Malard V, Gaillard JC, Berenguer F, Sage N, and Quemeneur E. 2009. Urine proteomic profiling of uranium nephrotoxicity. Biochim Biophys Acta 1794:882-891. 10.1016/j.bbapap.2009.01.010

Mesrobian HG, Mitchell ME, See WA, Halligan BD, Carlson BE, Greene AS, and Wakim BT. 2010. Candidate urinary biomarker discovery in ureteropelvic junction obstruction: a proteomic approach. J Urol 184:709-714. 10.1016/j.juro.2010.03.061

Nabe K, Honjo S, Ikeda H, Wada Y, Nomura K, Hamamoto Y, Koh T, Tatsuoka Y, and Koshiyama H. 2007. Diabetes insipidus and cognitive function. Med Hypotheses 69:764-766. 10.1016/j.mehy.2007.01.081

Nagaraj N, and Mann M. 2011. Quantitative analysis of the intra- and inter-individual variability of the normal urinary proteome. J Proteome Res 10:637-645. 10.1021/pr100835s

Ngai HH, Sit WH, Jiang PP, Thongboonkerd V, and Wan JM. 2007. Markedly increased urinary preprohaptoglobin and haptoglobin in passive Heymann nephritis: a differential proteomics approach. J Proteome Res 6:3313-3320. 10.1021/pr070245b

Old WM, Meyer-Arendt K, Aveline-Wolf L, Pierce KG, Mendoza A, Sevinsky JR, Resing KA, and Ahn NG. 2005. Comparison of label-free methods for quantifying human proteins by shotgun proteomics. Mol Cell Proteomics 4:1487-1502. 10.1074/mcp.M500084-MCP200

Palmer BF. 2000. Hyponatraemia in a neurosurgical patient: syndrome of inappropriate antidiuretic hormone secretion versus cerebral salt wasting. Nephrol Dial Transplant 15:262-268.

Pejcic M, Stojnev S, and Stefanovic V. 2010. Urinary proteomics--a tool for biomarker discovery. Ren Fail 32:259-268. 10.3109/08860221003599759

Phillips JA, Holder DJ, Ennulat D, Gautier JC, Sauer JM, Yang Y, McDuffie E, Sonee M, Gu YZ, Troth SP, Lynch K, Hamlin D, Peters DG, Brees D, and Walker EG. 2016. Rat Urinary Osteopontin and Neutrophil gelatinase-associated lipocalin Improve Certainty of Detecting Drug-Induced Kidney Injury. Toxicol Sci. 10.1093/toxsci/kfw038

Piras C, Soggiu A, Greco V, Cassinotti A, Maconi G, Ardizzone S, Amoresano A, Porro GB, Bonizzi L, and Roncada P. 2014. Serum protein profiling of early and advanced stage Crohn's disease. EuPA Open Proteomics 3:48-59.

Rainczuk A, Condina M, Pelzing M, Dolman S, Rao J, Fairweather N, Jobling T, and Stephens AN. 2013. The utility of isotope-coded protein labeling for prioritization of proteins found in ovarian cancer patient urine. $J$ Proteome Res 12:4074-4088. 10.1021/pr400618v

Rao PV, Lu X, Standley M, Pattee P, Neelima G, Girisesh G, Dakshinamurthy KV, Roberts CT, Jr., and Nagalla SR. 2007. Proteomic identification of urinary biomarkers of diabetic nephropathy. Diabetes Care 30:629-637. 10.2337/dc06-2056

Schaefer L, Han X, Gretz N, and Schaefer RM. 1996. Alterations of cathepsins B, H and L in proximal tubules from polycystic kidneys of the Han:SPRD rat. Kidney Int 50:424-431.

Schanstra JP, and Mischak H. 2015. Proteomic urinary biomarker approach in renal disease: from discovery to implementation. Pediatr Nephrol 30:713-725. 10.1007/s00467-014-2790-y

Schmidt C, Gronborg M, Deckert J, Bessonov S, Conrad T, Luhrmann R, and Urlaub H. 2014. Mass spectrometrybased relative quantification of proteins in precatalytic and catalytically active spliceosomes by metabolic labeling (SILAC), chemical labeling (iTRAQ), and label-free spectral count. Rna 20:406-420. 10.1261/rna.041244.113

Schultheis PJ, Clarke LL, Meneton P, Miller ML, Soleimani M, Gawenis LR, Riddle TM, Duffy JJ, Doetschman T, Wang T, Giebisch G, Aronson PS, Lorenz JN, and Shull GE. 1998. Renal and intestinal absorptive defects in mice lacking the NHE3 Na+/H+ exchanger. Nat Genet 19:282-285. 10.1038/969

Schwaller B. 2009. The continuing disappearance of "pure" Ca2+ buffers. Cell Mol Life Sci 66:275-300. 10.1007/s00018-008-8564-6

Spencer JD, Jackson AR, Li B, Ching CB, Vonau M, Easterling RS, Schwaderer AL, McHugh KM, and Becknell B. 2015. Expression and Significance of the HIP/PAP and Reglllgamma Antimicrobial Peptides during Mammalian Urinary Tract Infection. PLoS One 10:e0144024. 10.1371/journal.pone.0144024

Suh MJ, Tovchigrechko A, Thovarai V, Rolfe MA, Torralba MG, Wang J, Adkins JN, Webb-Robertson BJ, Osborne W, Cogen FR, Kaplowitz PB, Metz TO, Nelson KE, Madupu R, and Pieper R. 2015. Quantitative Differences in the Urinary Proteome of Siblings Discordant for Type 1 Diabetes Include Lysosomal Enzymes. J Proteome 
496

497

498

499

500

501

502

503

504

505

506

507

508

509

510

511

512

513

514

515

516

517

518

519

520

521

522

523

524

525

526

527

528

529

530

531

532

533

534

535
Res 14:3123-3135. 10.1021/acs.jproteome.5b00052

Thongboonkerd V, Chutipongtanate S, and Kanlaya R. 2006. Systematic evaluation of sample preparation methods for gel-based human urinary proteomics: quantity, quality, and variability. J Proteome Res 5:183-191. 10.1021/pr0502525

Togashi Y, Sakaguchi Y, Miyamoto M, and Miyamoto Y. 2012. Urinary cystatin C as a biomarker for acute kidney injury and its immunohistochemical localization in kidney in the CDDP-treated rats. Exp Toxicol Pathol 64:797-805. 10.1016/j.etp.2011.01.018

Treschan TA, and Peters J. 2006. The vasopressin system: physiology and clinical strategies. Anesthesiology 105:599612; quiz 639-540.

Trovato FM, Tognarelli JM, Crossey MM, Catalano D, Taylor-Robinson SD, and Trovato GM. 2015. Challenges of liver cancer: Future emerging tools in imaging and urinary biomarkers. World J Hepatol 7:2664-2675. 10.4254/wjh.v7.i26.2664

van Swelm RP, Laarakkers CM, Kooijmans-Otero M, de Jong EM, Masereeuw R, and Russel FG. 2013. Biomarkers for methotrexate-induced liver injury: urinary protein profiling of psoriasis patients. Toxicol Lett 221:219-224. 10.1016/j.toxlet.2013.06.234

Verbalis JG. 1984. An experimental model of syndrome of inappropriate antidiuretic hormone secretion in the rat. Am J Physiol 247:E540-553.

Vilella AJ, Severin J, Ureta-Vidal A, Heng L, Durbin R, and Birney E. 2009. EnsemblCompara GeneTrees: Complete, duplication-aware phylogenetic trees in vertebrates. Genome Res 19:327-335. 10.1101/gr.073585.107

Wisniewski JR, Zougman A, Nagaraj N, and Mann M. 2009. Universal sample preparation method for proteome analysis. Nat Methods 6:359-362. 10.1038/nmeth.1322

Wu J, and Gao Y. 2015. Physiological conditions can be reflected in human urine proteome and metabolome. Expert Rev Proteomics 12:623-636. 10.1586/14789450.2015.1094380

Yang J, Singh V, Chen TE, Sarker R, Xiong L, Cha B, Jin S, Li X, Tse CM, Zachos NC, and Donowitz M. 2014. NHERF2/NHERF3 protein heterodimerization and macrocomplex formation are required for the inhibition of NHE3 activity by carbachol. J Biol Chem 289:20039-20053. 10.1074/jbc.M114.562413

Yang N, Feng S, Shedden K, Xie X, Liu Y, Rosser CJ, Lubman DM, and Goodison S. 2011. Urinary glycoprotein biomarker discovery for bladder cancer detection using LC/MS-MS and label-free quantification. Clin Cancer Res 17:3349-3359. 10.1158/1078-0432.ccr-10-3121

Zager RA, Vijayan A, and Johnson AC. 2012. Proximal tubule haptoglobin gene activation is an integral component of the acute kidney injury "stress response". Am J Physiol Renal Physiol 303:F139-148. 10.1152/ajprenal.00168.2012

Zelena D, Domokos A, Jain SK, Jankord R, and Filaretova L. 2009. The stimuli-specific role of vasopressin in the hypothalamus-pituitary-adrenal axis response to stress. J Endocrinol 202:263-278. 10.1677/joe-09-0096

Zhang YG, Kuang ZJ, Mao YY, Wei RH, Bao SL, Wu LB, Li YG, and Tang CS. 2011. Osteopontin is involved in urotensin II-induced migration of rat aortic adventitial fibroblasts. Peptides 32:2452-2458. 10.1016/j.peptides.2011.10.018 
Figure 1

Physiological indicators of rats in control group $(n=7)$, low dose AVP group $(n=5)$ and high dose AVP group $(n=6)$.

A, weight gain of rats in three groups; $B$, urine protein-to-creatinine ratio of rats in three groups; C, 24 h urine volume of rats in three groups; D, urinary osmolality of rats in three groups.

A

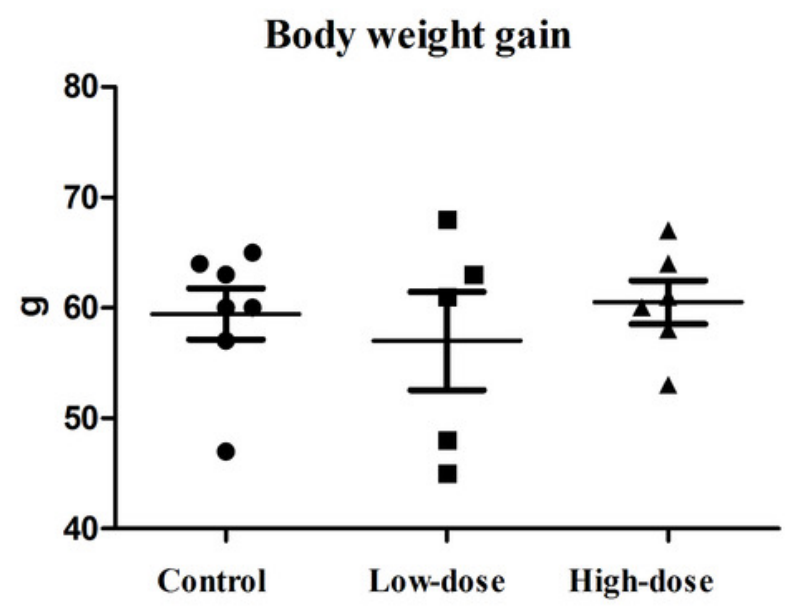

C

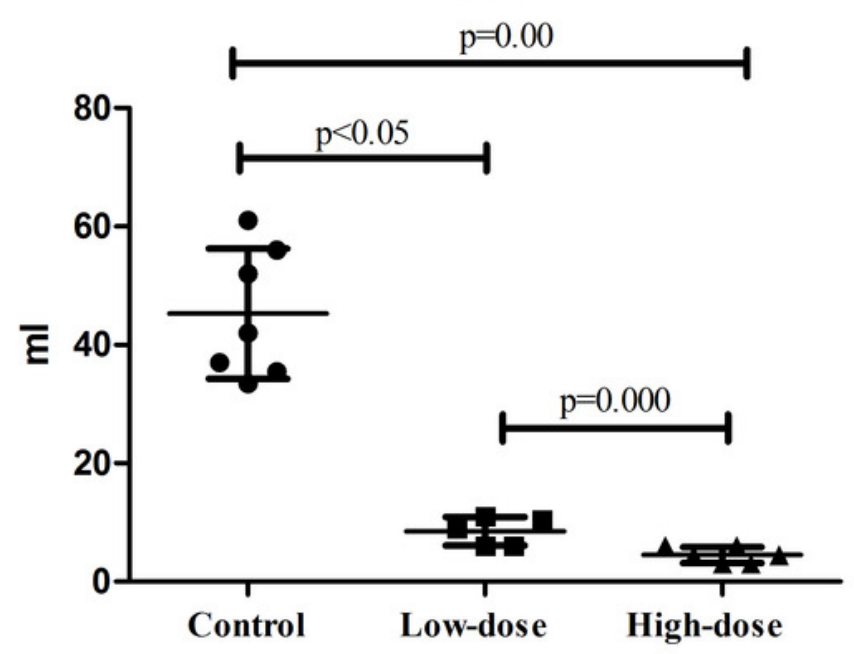

B

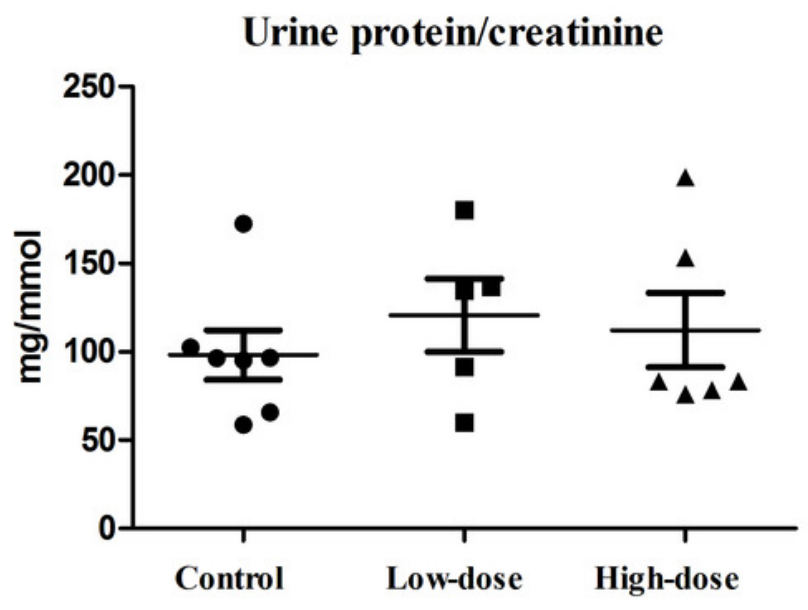

D Osmolality of urine

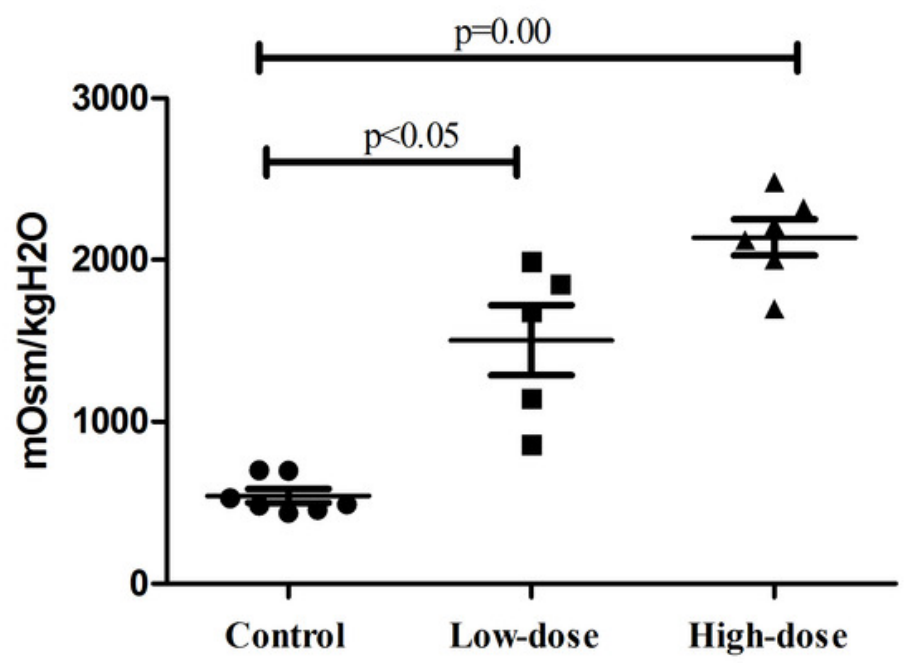




\section{Figure 2}

SDS-PAGE of urinary proteins in control group, low dose AVP group and high dose AVP group.

M, marker.

*Note: Auto Gamma Correction was used for the image. This only affects the reviewing manuscript. See original source image if needed for review.

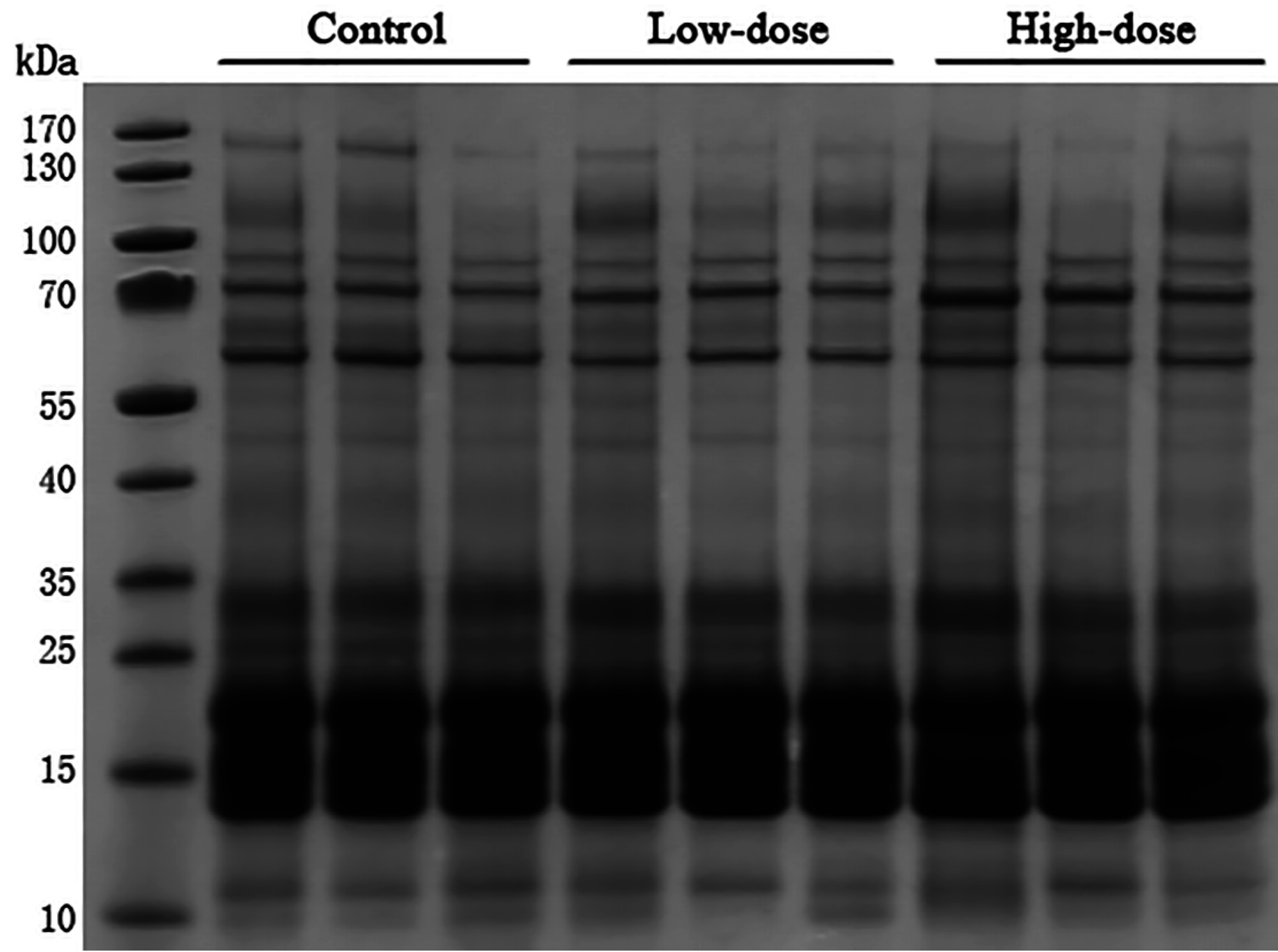


Figure 3 (on next page)

Heatmap of Hierarchical clustering.

$1,2,3$, control group; 4, 5, 6, low dose group; $7,8,9$, high dose group; $-1,-2,-3$, three technical replicates of each sample. 

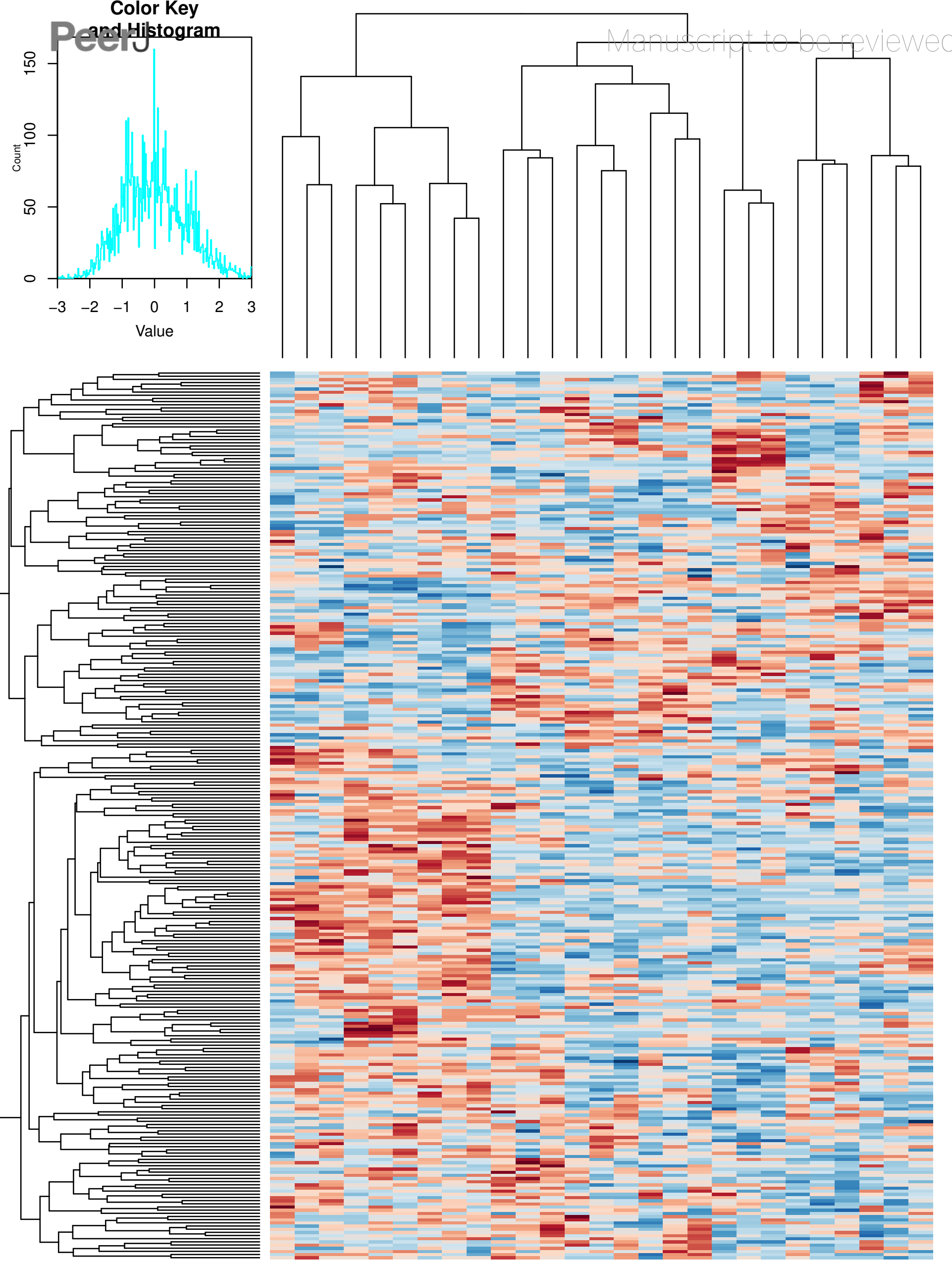

万人 


\section{Figure 4}

Biological function analysis of differential proteins between control group and AVP infusion groups.
A, molecular functions of differential proteins; $B$, biological processes of differential proteins;
C, cellular components of differential proteins. 
PANTHER GO-Slim Molecular Function Total \# Genes: 46 Total \# function hits: 63

A

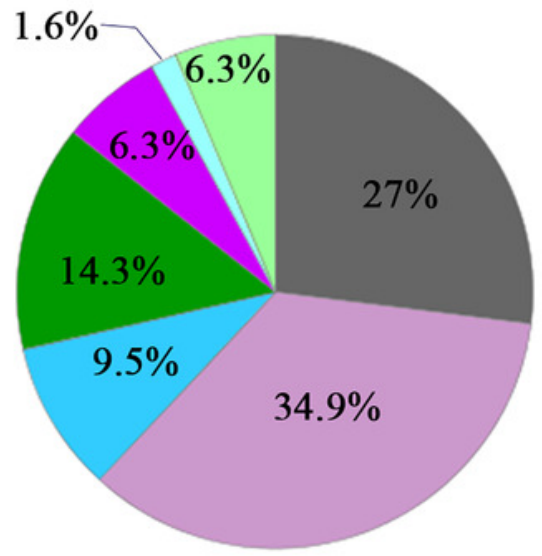

PANTHER GO-Slim Biological Process Total \# Genes: 46 Total \# process hits: 106

B

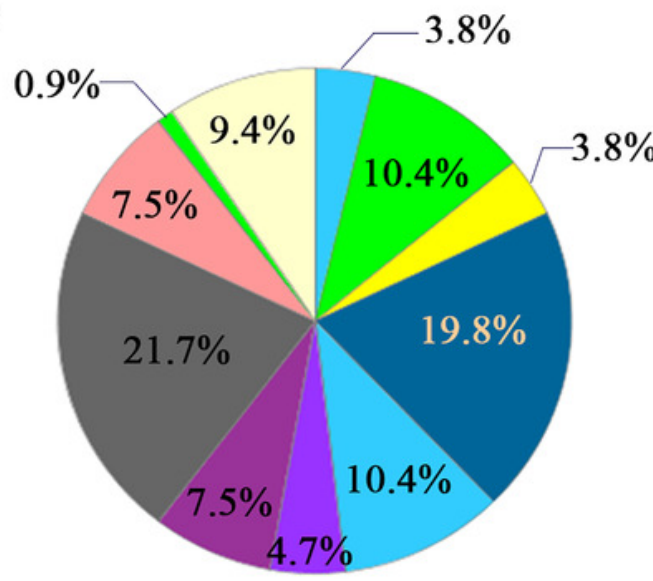

PANTHER GO-Slim Cellular Component Total \# Genes: 46 Trtal \# component hits: 23

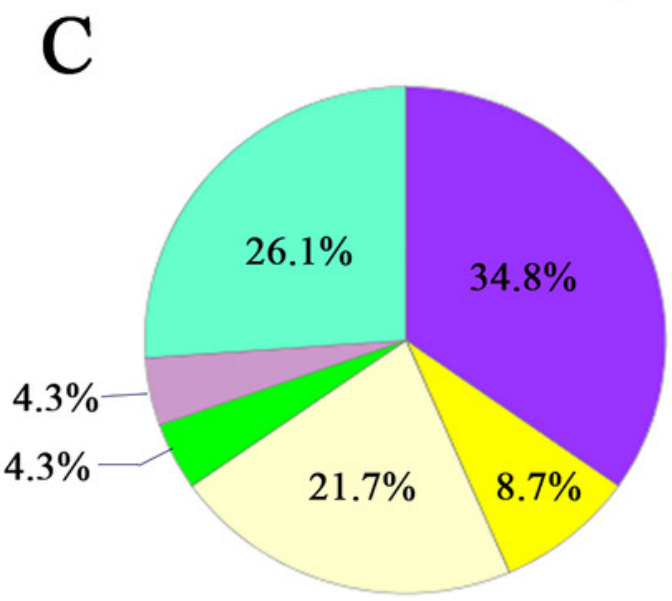

binding (GO:0005488)

catalytic activity (GO:0003824)

enzyme regulator activity (GO:0030234)

receptor activity (GO:0004872)

structural molecule activity (GO:0005198)

translation regulator activity (GO:0045182)

transporter activity (GO:0005215)

biological adhesion (GO:0022610)

biological regulation (GO:0065007)

cellular component organization or biogenesis (GO:0071840)

cellular process (GO:0009987)

developmental process (G0:0032502)

immune system process (G0:0002376)

localization (GO:0051179)

metabolic process (G0:0008152)

multicellular organismal process (GO:0032501)

reproduction (GO:0000003)

response to stimulus (GO:0050896) cell part (GO:0044464)

extracellular matrix (G0:0031012) extracellular region (GO:0005576)

macromolecular complex (GO:0032991)

membrane (GO:0016020)

organelle (GO:0043226) 


\section{Table $\mathbf{1}$ (on next page)}

The significant differential proteins between control group and low dose group.

Rat 1, 2, 3, control group; rat 4, 5, 6, low-dose group; fold change is low dose-to-control group ratio. 
1 Table 1 The significant differential proteins between control group and low dose group.

2 Rat 1, 2, 3, control group; rat 4, 5, 6, low-dose group; fold change is low dose-to-control group ratio.

3

\begin{tabular}{|c|c|c|c|c|c|c|c|c|c|c|}
\hline \multirow[b]{2}{*}{ Protein name } & \multirow{2}{*}{$\begin{array}{l}\text { Accession } \\
\text { number }\end{array}$} & \multirow{2}{*}{$\begin{array}{l}\text { Fold } \\
\text { change }\end{array}$} & \multirow{2}{*}{$\begin{array}{l}\mathrm{P} \\
\text { value }\end{array}$} & \multicolumn{6}{|c|}{ Spectral counts } & \multirow{2}{*}{$\begin{array}{l}\text { Candidate } \\
\text { biomarker }\end{array}$} \\
\hline & & & & Rat 1 & Rat 2 & Rat 3 & Rat 4 & Rat 5 & Rat 6 & \\
\hline Haptoglobin & HPT_RAT & 2.33 & 0.022 & 6 & 3 & 3 & 10 & 8 & 10 & Yes \\
\hline $\begin{array}{l}\text { Prolactin-inducible protein } \\
\text { homolog }\end{array}$ & PIP_RAT & 1.88 & 0.009 & 2 & 3 & 3 & 5 & 6 & 4 & No \\
\hline Pro-cathepsin H & CATH_RAT & 1.88 & 0.041 & 2 & 3 & 3 & 5 & 5 & 5 & Yes \\
\hline $\begin{array}{l}\text { Junctional adhesion molecule } \\
\text { A }\end{array}$ & JAM1_RAT & 0.66 & 0.005 & 8 & 9 & 7 & 5 & 6 & 5 & No \\
\hline $\begin{array}{l}\text { Regenerating islet-derived } \\
\text { protein 3-gamma }\end{array}$ & REG3G_RAT & 0.60 & 0.011 & 18 & 16 & 14 & 8 & 13 & 8 & Yes \\
\hline $\begin{array}{l}\text { Glutamate--cysteine ligase } \\
\text { catalytic subunit }\end{array}$ & GSH1_RAT & 0.60 & 0.020 & 11 & 11 & 8 & 4 & 8 & 6 & No \\
\hline Attractin & ATRN_RAT & 0.56 & 0.041 & 5 & 7 & 4 & 2 & 4 & 3 & No \\
\hline $\begin{array}{l}\text { Malate dehydrogenase, } \\
\text { cytoplasmic }\end{array}$ & MDHC_RAT & 0.46 & 0.005 & 4 & 6 & 5 & 3 & 2 & 2 & No \\
\hline
\end{tabular}




\section{Table 2 (on next page)}

The significant differential proteins between control group and high dose group.

Rat 1, 2, 3, control group; rat 7, 8, 9, high-dose group; fold change is high dose-to-control group ratio. 
1 Table 2 The significant differential proteins between control group and high dose group.

2 Rat 1, 2, 3, control group; rat 7, 8, 9, high-dose group; fold change is high dose-to-control group ratio.

3

\begin{tabular}{|c|c|c|c|c|c|c|c|c|c|c|}
\hline \multirow[b]{2}{*}{ Protein name } & \multirow{2}{*}{$\begin{array}{l}\text { Accession } \\
\text { number }\end{array}$} & \multirow{2}{*}{$\begin{array}{l}\text { Fold } \\
\text { change }\end{array}$} & \multirow{2}{*}{$\begin{array}{l}P \\
\text { value }\end{array}$} & \multicolumn{5}{|c|}{ Spectral counts } & \multirow[b]{2}{*}{ Rat 9} & \multirow{2}{*}{$\begin{array}{l}\text { Candidate } \\
\text { biomarkers }\end{array}$} \\
\hline & & & & Rat 1 & Rat 2 & Rat 3 & Rat 7 & Rat 8 & & \\
\hline Osteopontin & OSTP_RAT & 6.00 & 0.038 & 0 & 0 & 4 & 7 & 9 & 8 & Yes \\
\hline Calbindin & CALB1_RAT & 5.17 & 0.019 & 2 & 4 & 0 & 5 & 12 & 14 & Yes \\
\hline Putative phospholipase B-like 2 & PLBL2_RAT & 3.50 & 0 & 1 & 2 & 1 & 5 & 5 & 4 & No \\
\hline $\begin{array}{l}\text { Cluster of Glyceraldehyde-3- } \\
\text { phosphate dehydrogenase }\end{array}$ & G3P_RAT & 2.17 & 0.018 & 2 & 3 & 1 & 5 & 4 & 4 & Yes \\
\hline CD166 antigen & CD166_RAT & 1.75 & 0.050 & 3 & 3 & 2 & 6 & 4 & 4 & Yes \\
\hline Complement $\mathrm{C} 3$ & CO3_RAT & 1.71 & 0.045 & 9 & 8 & 7 & 10 & 17 & 14 & Yes \\
\hline Beta-2-glycoprotein 1 & APOH_RAT & 1.70 & 0.048 & 3 & 4 & 3 & 5 & 5 & 7 & Yes \\
\hline $\begin{array}{l}\mathrm{Na}(+) / \mathrm{H}(+) \text { exchange regulatory } \\
\text { cofactor NHE-RF3 }\end{array}$ & NHRF3_RAT & 1.58 & 0.026 & 7 & 6 & 11 & 12 & 14 & 12 & No \\
\hline Copper transport protein ATOX1 & ATOX1_RAT & 1.53 & 0.013 & 6 & 4 & 5 & 7 & 7 & 9 & No \\
\hline $\begin{array}{l}\text { Regenerating islet-derived } \\
\text { protein 3-gamma }\end{array}$ & REG3G_RAT & 0.46 & 0.003 & 18 & 16 & 14 & 8 & 8 & 6 & Yes \\
\hline
\end{tabular}




\section{Table 3 (on next page)}

Human orthologs of the significant differential proteins between control group and AVP infusion groups. 
Table 3 Human orthologs of the significant differential proteins between control group and AVP infusion groups.

\begin{tabular}{|c|c|c|c|c|}
\hline Protein name & $\begin{array}{l}\text { Rat protein accession } \\
\text { number }\end{array}$ & $\begin{array}{l}\text { Human ensembl } \\
\text { gene ID }\end{array}$ & $\begin{array}{l}\text { Human protein } \\
\text { accession number }\end{array}$ & $\begin{array}{l}\text { Human core urinary } \\
\text { proteome }\end{array}$ \\
\hline Haptoglobin & HPT_RAT & ENSG00000257017 & HPT_HUMAN & Yes \\
\hline Prolactin-inducible protein homolog & PIP_RAT & ENSG00000159763 & PIP_HUMAN & Yes \\
\hline Pro-cathepsin $\mathrm{H}$ & CATH_RAT & ENSG00000103811 & CATH_HUMAN & Yes \\
\hline Junctional adhesion molecule A & JAM1_RAT & ENSG00000158769 & JAM1_HUMAN & Yes \\
\hline Regenerating islet-derived protein 3-gamma & REG3G_RAT & ENSG00000172016 & REG3A_HUMAN & No \\
\hline Glutamate--cysteine ligase catalytic subunit & GSH1_RAT & ENSG00000001084 & GSH1_HUMAN & No \\
\hline Attractin & ATRN_RAT & ENSG00000088812 & ATRN_HUMAN & Yes \\
\hline Malate dehydrogenase, cytoplasmic & MDHC_RAT & ENSG00000014641 & MDHC_HUMAN & Yes \\
\hline Osteopontin & OSTP_RAT & ENSG00000118785 & OSTP_HUMAN & Yes \\
\hline Calbindin & CALB1_RAT & ENSG00000104327 & CALB1_HUMAN & Yes \\
\hline Putative phospholipase B-like 2 & PLBL2_RAT & ENSG00000151176 & PLBL2_HUMAN & Yes \\
\hline Cluster of Glyceraldehyde-3-phosphate dehydrogenase & G3P_RAT & ENSG00000111640 & G3P_HUMAN & Yes \\
\hline CD166 antigen & CD166_RAT & ENSG00000170017 & CD166_HUMAN & No \\
\hline Beta-2-glycoprotein 1 & APOH_RAT & ENSG00000091583 & APOH_HUMAN & Yes \\
\hline $\mathrm{Na}(+) / \mathrm{H}(+)$ exchange regulatory cofactor NHE-RF3 & NHRF3_RAT & ENSG00000174827 & NHRF3_HUMAN & No \\
\hline Copper transport protein ATOX1 & ATOX1_RAT & ENSG00000177556 & ATOX1_HUMAN & Yes \\
\hline
\end{tabular}

